\title{
Family Conflict Resolution: Its Measurement and Relationship with Family Conflict and Psychological Adjustment
}

\author{
P. Tyler Roskos, Paul J. Handal, Megan E. Ubinger \\ School of Medicine, Saint Louis University, Saint Louis, USA. \\ Email: roskospt@slu.edu \\ Received June $7^{\text {th }}, 2010$; revised August $4^{\text {th }}, 2010$; accepted August $9^{\text {th }}, 2010$.
}

\begin{abstract}
Based on family conflict literature, there is a need for the development of a measure of family conflict resolution. This study aimed to develop items based on established instruments and rationally construct new items in order to pilot a measure of family conflict resolution. Preliminary reliability and validity data were obtained using a sample of young adults. Results indicate that the proposed measure of conflict resolution produced valid factor analytic solutions, adequate internal consistency, and construct validity. The results of this study also revealed avoidance of conflict as a factor that is related to adjustment. Future research into conflict avoidance as a salient contributor to psychological adjustment appears warranted.
\end{abstract}

Keywords: Family Conflict, Conflict Resolution, Adjustment

\section{Introduction}

A review of the empirical literature has revealed a clear relationship between conflict and adjustment. Interparental conflict has been demonstrated to have a negative effect on the adjustment of children (Cummings, Goeke-Morey, Papp, \& Dukewich, 2002; Davies \& Cummings, 1994; El-Sheikh, M., 1997) while research into the area of perceived family conflict has demonstrated both statistically significant and clinically meaningful results for children (Handal, Tschannen, \& Searight, 1998), adolescents (Borrine, Handal, Brown, \& Searight, 1991) and young adults (Nelson, Hughes, Handal, \& Katz, 1993). Results of these studies have demonstrated that children, adolescents, and young adults who perceive high levels of family conflict score above the cutoff on an epidemiological measure of distress, while children, adolescents, and young adults who perceive low levels of conflict in their families score below the cutoff score.

Since the deleterious aspects of conflict within the context of a family are now strongly supported, conflict research has more recently been concerned with the potential positive aspects of conflict resolution on adjustment. For example, Davies and Cummings (1994) hypothesized that if conflicts are solved, they are less likely to be viewed negatively by the child and, therefore, adjustment problems may not develop. In a laboratory study, Cummings, Iannotti, and Zahn-Waxler (1985) reported that children's aggression and distress reduced to baseline levels after exposure to conflict resolution between parents. Furthermore, Cummings, Ballard, El-Sheikh, and Lake (1991) demonstrated that children exposed to interparental conflict that was unresolved had significantly greater angry reactions than children who viewed partially or fully resolved interparental conflicts.

Research in the area of family conflict resolution has focused on resolved parental conflict (couples) and resolution has typically been measured in a dichotomous manner within a laboratory setting (resolved conflict versus unresolved conflict;
Cummings, et al., 1991). Also, laboratory studies have measured conflict resolution in couples based on behavioral observations during marital conflict resolution (DuRocher-Schudlich, Papp, \& Cummings, 2004). Overall, research involving interparental conflict resolution shows that it is a potential buffer for adjustment difficulties in children. However, more research must be conducted in order to better measure conflict resolution in order to draw conclusions about its meaningfulness in relation to adjustment. Development and validation of a self-report measure that assesses family conflict resolution as perceived by the child, adolescent, or young adult would be a necessary step in this area of empirical investigation.

Instruments such as the Family Environment Scale (FES; Moos \& Moos, 1986) and the Children's Perceptions of Interparental Conflict Scale (CPIC; Grych, Seid, \& Fincham, 1992) have been established as measures of family conflict, but do not include a family conflict resolution factor. The CPIC also only focuses on how children view conflict between parents, limiting its utility in measuring conflict resolution within other family relationships. The Revised Conflict Tactics Scale (CTS2; Straus, Hamby, Boney-McCoy, \& Sugarman, 1996) also purports to measure the use of reasoning and negotiation to deal with conflicts. However, like the CPIC, this measure focuses on disputes between couples, as opposed to family conflict and conflict resolution. While these instruments have been shown to be reliable and valid tools to assess conflict within the family, they are perhaps limited as measures of family conflict resolution.

In order to gain a better understanding of what constitutes family conflict resolution and how it may relate to adjustment, development of a specific measure is needed. Ideally, this instrument would sensitively measure family conflict resolution, allowing for the clarification of the potential relationship between family conflict resolution and psychological adjustment. A better understanding of conflict resolution would also have clinical implications for working with children, adolescents, and young adults and their families regarding conflict. 
The aim of this study was to develop a measure of perceived family conflict resolution and to provide pilot reliability and validity data for this instrument. This measure contains items modeled after other established family conflict measures (Conflict Tactics Scale, Children's Perceptions of Interparenal Conflict Scale, etc.) with empirically sound reliability and validity, as described above, as well as newly-developed items aimed at tapping the construct of family conflict resolution.

\section{Method}

Data for this study were collected as a part of a larger unpublished investigation of family conflict and psychological adjustment (Roskos, 2004). In the following, a brief description of the procedure and measures used will be provided.

\section{Participants}

Participants in this study were 332 (98 males and 234 females) young adults drawn from an urban, Midwestern, Catholic university. Twenty-nine percent of the participants were 18 years of age, $28 \%$ were $19,21.7 \%$ were $20,13.3 \%$ were 21 , $5.4 \%$ were 22 , and $1.8 \%$ were 23 or older (mean age $=19.4, S D$ $=1.29)$. They were mostly Caucasian $(85.2 \%)$, with other ethnicities represented as follows: 6.6\% African American, 4.2\% Asian American, 1.0\% Hispanic, and 2.1\% other. Participants generally came from intact two-parent families (74.4\%), 12\% reported coming from divorced families, $7.2 \%$ reported having a single parent, $3.6 \%$ had parents who were remarried, and $1.5 \%$ had one widowed parent. Participants were primarily of middle to upper-middle socioeconomic status as determined by participants' report of their mother and father's income and educational/occupational levels. The majority of participants $(\mathrm{N}$ $=169,51 \%$ ) lived in on-campus dormitory housing. Only $14 \%$ $(\mathrm{N}=45)$ of the sample was living at home with their family at the time the study was conducted.

\section{Measures}

The conflict scale of The Family Environment Scale (FES; Moos \& Moos, 1986) was used to measure the participants' views of family conflict. The FES is a 90 -item true-false instrument that yields standard scores on 10 subscales. It is widely used as a measure of family climate and how it relates to psychological adjustment (Nelson, Hughes, Handal, \& Katz, 1993; Handal, LeStiebel, Dicarlo, \& Gutzwiller, 1999; Kleinman, Handal, Enos, Searight, \& Ross, 1989). The conflict scale consists of nine items that assess the amount of expressed anger, aggression, and conflict among family members. Kleinman, et al. (1989) validated cut off scores for high (more than one standard deviation above the mean) and low conflict (more than one standard deviation below the mean) families based on scores on the conflict scale. The mean score on the conflict subscale in the normative sample was $3.18(\mathrm{SD}=1.91)$, the internal consistency (Cronbach's $\alpha$ ) was .75, and the two-month test-retest reliability was .85 (Moos \& Moos, 1986).

The Family Conflict Resolution Scale (FCRS) was developed to assess conflict resolution in the family. Items were developed through a literature search that yielded several measures with items that tapped into the construct of conflict resolution, such as the CPIC (Grych, et al., 1992), the FES, and the RCTS (Straus, et al., 1996; Straus, 1979). Items that appeared appropriate from these measures served as models for development of items on the FCRS. In addition, items were rationally constructed that appeared content valid. A pool of such items was created and reviewed by two graduate students and a research supervisor. The reviewers compiled a total of 18 items deemed to be appropriate measures of family conflict resolution. Of the 18 items, 17 are summed to provide a total score for family conflict resolution. Of those, 14 items were answered using a true/false response format. An example of such an item would include "In my family, when we have an argument we usually work it out." Items 15,16 , and 17 are answered using a 7-point Likert scale ranging from 1 "never" to 7 "always." For example, item 15 states "We tend to avoid each other when we have a disagreement." The range of scores was 0-32, with higher scores indicating higher levels of conflict resolution. The three items using a Likert scale were included to ensure adequate variance on this preliminary version of the scale. For the purposes of initial examination of the construct of family conflict resolution in this project, a total score on the FCRS was used in analyses, despite true/false and Likert items being unevenly weighted in calculating the total score. The last item on the measure (Item 18) required the respondent to choose the category (avoidance of the problem, excessive yelling, fighting, and/or arguing, or resolution and/or satisfactorily solved) that best described how their family's disagreements were handled. This item was not included as a part of the total score for family conflict resolution. It was used as a self-report, categorical measure of how participants perceive conflict to be typically addressed in their family.

The Brief Symptom Inventory (BSI; Derogatis \& Spencer, 1982 ) is an abbreviated version of the Symptom Checklist-90Revised self-report measure of current psychiatric symptoms. The Global Severity Index (GSI), which is an average of the scores for the 53 BSI items, was used as an indicator of overall level of distress and adjustment difficulty. Scores at or above a T-score of 63 are considered clinically significant. The overall test-retest reliability for a two-week interval for the BSI is .90. Cochran and Hale (1985) conducted a normative study for the BSI using a young adult college sample. They found that young adult college students reported significantly higher levels of distress and different patterns of distress than younger adolescents and older adults. The mean GSI for college males is .84 $(\mathrm{SD}=.55)$ and for college females is .71 $(\mathrm{SD}=.42)$.

The Langner Symptom Survey (LSS; Langner, 1962) was used as a measure of overall current psychological maladjustment. The LSS consists of 22 items that are scored 0 or 1 , indicating the presence or absence of a psychiatric symptom. Langner reported that a cutoff score of four or greater differentiated patients from non-patients and correctly identified $84 \%$ of those with psychological difficulties. The mean score for outpatients was $4.78(\mathrm{SD}=3.27)$, for ex-patients $4.20(\mathrm{SD}=$ $3.35)$, and for non-patients $2.60(\mathrm{SD}=2.67)$. The LSS has an overall internal consistency (Cronbach's $\alpha$ ) of .80. Handal, Gist, Gilner, and Searight (1993) reported that the LSS, using a cutoff score of four or more, accurately identified $82 \%$ of adolescents not in treatment, $76 \%$ of adolescents in outpatient treatment, and $79 \%$ of adolescents in inpatient treatment. Because participants self-reported both perceived family conflict and adjustment, the LSS was used to minimize common method variance because of its strong concurrent validity data. 
The Flanagan Life Satisfaction Questionnaire (FLSQ; Flanagan, 1978) was included as a measure of positive psychological adjustment. Participants rated their overall satisfaction on 13 life domains using a 6-point Likert scale. Scores range from 13-78, with higher scores representing higher life satisfaction. Handal and Moore (1987) established the concurrent validity of the FLSQ when comparing it to the LSS.

Also included was a demographic questionnaire in order to gather information concerning participants' age, gender, yearlevel in college, religion, race, residence, parental education and occupation, parent's marital status, and psychiatric history.

\section{Procedure}

Following institutional review board approval, participants were recruited from undergraduate psychology courses and received extra credit as compensation for their participation. A brief description of the study was read to psychology classes and packets that included the previously described instruments were distributed to individuals who wanted to participate. In order to control for the possibility that sequencing of measures might influence responding, two forms were developed (Form A and Form B). Form A had items related to adjustment first with items relating to family conflict and conflict resolution following. Form B started with family conflict items, with items related to adjustment following. Approximately 51\% (N $=171)$ of participants completed form A and approximately $49 \%(\mathrm{~N}=161)$ completed form B. Sealed envelopes containing the completed questionnaires were returned to the experimenter before each class within one week after distribution.

\section{Results}

\section{Participant and Measure Characteristics}

Using MANOVA, no significant effects were observed for item order (form A or form B), gender, or grade level on the set of dependent measures (the three adjustment measures, the conflict measure, and the conflict resolution measure; Roskos, 2004). Consequently, data from form A and form B, for males and females, and for all college grade levels were collapsed for further analyses.

Table 1 includes means, standard deviations, and an intercorrelation matrix for the collapsed sample on all dependent variables. The sample mean for the GSI is consistent with the reported findings of Cochran and Hale (1985) for college students, which is higher than those reported for an adult population. In addition, the mean family conflict score and the internal consistency $(\alpha=.75)$ for this sample are consistent with the mean and alpha reported by Moos and Moos (1986). Cronbach's alpha coefficient was calculated to determine the internal consisten cy of the FCRS and the result was $\alpha=.87$. This suggests that the items that make up the FCRS have high internal consistency reliability.

\section{Perceived Family Conflict}

Analyses of conflict data in relation to measures of adjustment were conducted in order to attempt to replicate relationships previously observed in the literature. Participants were divided into groups based on FES scores as follows: high con- flict ( $>1$ SD above the mean), middle conflict (within 1 SD above and below the mean); and low conflict ( $>1$ SD below the mean). As seen in Table 1, findings showed that family conflict was significantly correlated with measures of psychological maladjustment (LSS R $=.35$ and GSI $\mathrm{R}=.35$ ) and negatively correlated with a measure of life satisfaction (FLSQ $\mathrm{R}=-.29$ ). Multivariate (MANOVA: Wilks' $\lambda=.89 ; \mathrm{F}_{6,654}=6.37 ; \mathrm{p}$ $<.001)$ and follow-up univariate analyses of variance showed that a high conflict group was statistically and significantly different from middle and low conflict groups (i.e. greater levels of maladjustment) on both the LSS $\left(\mathrm{F}_{2,329}=16.75, \mathrm{p}\right.$ $<.001)$ and the GSI $\left(\mathrm{F}_{2,329}=15.62, \mathrm{p}<.001\right)$, which is consistent with findings from previous literature regarding the relationship between family conflict and psychological adjustment.

\section{Perceived Family Conflict Resolution}

In examining the construct validity of the FCRS, Pearson correlation analyses were conducted. The correlation matrix is displayed in Table 1 . These results showed a statistically significant negative correlation $(\mathrm{R}=-.68)$ between family conflict and a family conflict resolution. This would suggest that family conflict and family conflict resolution are related, but somewhat distinct constructs. In addition, correlations between the FCRS and measures of psychological maladjustment were found to be statistically significant in a negative direction. On the other hand, correlations between the FCRS and a measure of positive adjustment were statistically significant in a positive direction. These findings suggest significant relationships between family conflict resolution and psychological adjustment.

In order to establish if family conflict resolution relates to outcome measures of adjustment at statistically significant and clinically meaningful levels, a MANOVA was conducted using high (greater than $1 \mathrm{SD}$ above the mean), middle (within $1 \mathrm{SD}$ above and below the mean), and low (greater than 1 SD below the mean) family conflict resolution groups as the fixed factor and the three measures of adjustment as the dependent variables. Results of those analyses yielded a statistically significant MANOVA F: Wilks' $\lambda=.79, \mathrm{~F}=13.36, \mathrm{p}=.001$. Follow-up univariate one-way ANOVAs were conducted and yielded significant differences on each of the three DVs. Consequently,

Table 1.

Sample descriptive statistics and correlation matrix for all dependent variables.

\begin{tabular}{|c|c|c|c|c|c|c|}
\hline & & & & \multicolumn{3}{|c|}{ Pearson Correlations } \\
\hline $\begin{array}{c}\text { Dependent } \\
\text { Variable }\end{array}$ & $\begin{array}{l}\text { Mean } \\
(S D)\end{array}$ & LSS & GSI & FSLQ & $\mathrm{FC}$ & FR \\
\hline LSS & $\begin{array}{c}4.23 \\
(3.42)\end{array}$ & 1.0 & $.75^{* *}$ & $-.55^{* *}$ & $.35^{* *}$ & $-.41^{* *}$ \\
\hline GSI & $\begin{array}{c}.74 \\
(.59)\end{array}$ & & 1.0 & $-.61^{* *}$ & $.35^{* *}$ & $-.42^{* *}$ \\
\hline FSLQ & $\begin{array}{c}58.87 \\
(11.91)\end{array}$ & & & 1.0 & $-.29^{* *}$ & $.45^{* *}$ \\
\hline FC & $\begin{array}{c}3.18 \\
(2.28)\end{array}$ & & & & 1.0 & $-.68^{* *}$ \\
\hline FR & $\begin{array}{l}20.43 \\
(6.74)\end{array}$ & & & & & 1.0 \\
\hline
\end{tabular}

Note. LSS = Langner Symptom Survey; GSI = Global Severity Index; FSLQ = Flanagan Satisfaction With Life Questionnaire; FC = Family Conflict; FR = Family Resolution; ${ }^{* *} \mathrm{p}<.01$, two-tailed. 
Tukey HSD post-hoc comparisons were performed to determine which conflict resolution groups differed on which DVs. As can be seen in Table 2, in general, individuals with high family conflict resolution showed lower levels of distress and maladjustment and higher levels of life satisfaction and positive adjustment. Scores on the LSS between high and low conflict resolution groups were both statistically significant and clinically meaningful because the low conflict resolution group mean score was above the cutoff for clinical caseness on the LSS.

Using the same method to assign groups, a second MANOVA was conducted to determine whether the 14-item true-false conflict resolution scale, with the Likert items omitted, would yield the same results as the full FCRS. Results showed a significant MANOVA F (Wilks' $\lambda=.84, F_{6,650}=9.99, p<.001$ ), with there being similar results to the first MANOVA that included Likert items in the FCRS score. However, the scores on the 14-item FCRS were skewed in a positive direction, with high FCRS scores (greater than 1 standard deviation above the mean) including scores of 14, middle FCRS scores (between 1 standard deviation above and below the mean) ranging from 6 to 13 and low FCRS scores (greater than 1 standard deviation below the mean) ranging from 0 to 5 .

To examine the FCRS item content, a principal component analysis was conducted. The categorical item from the instrument was excluded from this analysis. The eigenvalue greater than one criterion was used to choose factors and a cutoff of .50 was used to determine items that loaded onto a given factor. Two factors were extracted, accounting for $53.18 \%$ of the variance in the items after varimax rotation. All 17 items included in the analysis loaded onto a factor, with only one item loading onto both factors. The first factor included items that appeared to address aspects of positive family conflict resolution - coming to a solution, effective communication, and discussion of differences. The first factor also contained items that are representative of neither positive nor negative resolution. Items such as, "In my family, we can agree to disagree," are neutral in their implications for conflict resolution. The second factor consisted of items that imply negative resolution. One item ("In my family, we tend to resolve/solve our problems in a mutually satisfying way when we have a disagreement") loaded on both factor 1 and factor 2 . Table 3 provides the rotated factor loadings and a summary of this principal component analysis.

Table 2.

ANOVA results for family conflict resolution and adjustment measures.

\begin{tabular}{cccccc}
\hline Measure & F-Statistic & $\begin{array}{c}\text { Tukey HSD } \\
\text { comparisons }\end{array}$ & $\begin{array}{c}\text { Conflict } \\
\text { group }\end{array}$ & $M$ & SD \\
\hline LSS & $29.59^{* * *}$ & $\mathrm{~L}>\mathrm{M}>\mathrm{H}$ & $\mathrm{L}(\mathrm{N}=57)$ & 6.68 & 3.71 \\
& & & $\mathrm{M}(\mathrm{N}=205)$ & 4.18 & 3.28 \\
& & & $\mathrm{H}(\mathrm{N}=70)$ & 2.36 & 2.13 \\
GSI & \multirow{2}{*}{$28.59^{* * *}$} & $\mathrm{~L}>\mathrm{M}>\mathrm{H}$ & $\mathrm{L}(\mathrm{N}=57)$ & 1.15 & .60 \\
& & & $\mathrm{M}(\mathrm{N}=205)$ & .73 & .58 \\
& & & $\mathrm{H}(\mathrm{N}=70)$ & .42 & .38 \\
FSLQ & \multirow{3}{*}{$31.73^{* * *}$} & $\mathrm{~L}<\mathrm{M}<\mathrm{H}$ & $\mathrm{L}(\mathrm{N}=57)$ & 50.25 & 9.97 \\
& & & $\mathrm{M}(\mathrm{N}=205)$ & 58.91 & 11.94 \\
& & & $\mathrm{H}(\mathrm{N}=70)$ & 65.79 & 11.91 \\
\hline
\end{tabular}

Note. $\mathrm{L}=$ low conflict resolution group, $\mathrm{M}=$ middle conflict resolution group, and $\mathrm{H}=$ high conflict resolution group; ${ }^{* * *} \mathrm{p}<.001$.

Table 3.

Rotated Factor Matrix for Family Conflict Resolution (FCRS).

\begin{tabular}{|c|c|c|c|}
\hline FCRS items (all begin with stem: "In my family,") & Factor 1 & Factor 2 & Communalities \\
\hline When we disagree on issues, we can come to a resolution/solution. & .837 & .190 & .737 \\
\hline We can openly discuss our differences. & .766 & .141 & .606 \\
\hline When we have an argument, we usually come to a resolution. & .763 & .256 & .648 \\
\hline When we have an argument we usually work it out. & .695 & .293 & .569 \\
\hline We can effectively communicate about issues. & .680 & .310 & .559 \\
\hline When we disagree about something, we usually come up with a solution. & .679 & .350 & .584 \\
\hline When we have a disagreement, we usually come to a mutually agreeable solution. & .646 & .355 & .543 \\
\hline We tend to resolve/solve our problems in a mutually satisfying way when we have a disagreement. & .614 & .523 & .651 \\
\hline We can identify issues on which we differ. & .608 & $<.100$ & .371 \\
\hline We usually can accept each other's differences. & .591 & .269 & .422 \\
\hline We can agree to disagree. & .526 & .157 & .301 \\
\hline We still act mean after we have had an argument. & .136 & .755 & .589 \\
\hline We tend to avoid each other when we have a disagreement. & .170 & .695 & .512 \\
\hline Even after we stop arguing, we stay mad at each other. & .233 & .691 & .531 \\
\hline After we stop arguing, we are friendly toward each other. & .295 & .670 & .536 \\
\hline We tend to excessively yell, argue, and fight with each other when we have a disagreement. & .173 & .642 & .442 \\
\hline When we argue we usually make up right away. & .232 & .621 & .440 \\
\hline Rotated $\lambda$ (eigenvalues) & 5.34 & 3.70 & \\
\hline$\%$ of total variance each component accounts for after the rotation & 31.40 & 21.77 & \\
\hline
\end{tabular}

Note. Varimax rotation solution presented. The extracted factors were named as follows: Factor 1: Positive/Neutral Family Conflict Resolution and Factor 2: Negative Family Conflict Resolution. 
Data were also analyzed from the categorical item on the FCRS (item 18), which asked participants to determine how conflict is typically addressed in their family. Participants responded to this item by identifying whether conflict in their family is characterized by "avoidance," "excessive conflict," or "resolution." They were divided into avoidance, excessive conflict, or resolution groups for these analyses. A one-way MANOVA was computed using avoidance, excessive conflict, and resolution groups as the IV and measures of adjustment and conflict as DVs. Results yielded a significant MANOVA: Wilks' $\lambda=.67, \mathrm{~F}=17.57, \mathrm{p}<.001$. Univariate one-way ANOVAs were conducted as a follow-up showing significant differences on each DV. These findings are reported in Table 4 with Tukey HSD post-hoc comparisons between groups.

As seen in Table 4, the conflict resolution group had greater life satisfaction than either avoidance of conflict or excessive conflict. On the other hand, avoidance and excessive conflict groups had higher levels of maladjustment. Furthermore, it is important to highlight that a difference between the excessive conflict and avoidance groups on measures of maladjustment and life satisfaction was not found. It is notable that results for the LSS revealed that both the excessive $(M=5.55)$ and avoidance $(M=5.23)$ groups scored in the clinically meaningful distressed range compared to the resolution group $(M=3.37)$, which scored in the non-distressed range. When examining the Tukey HSD post-hoc comparisons when the family conflict score served as the DV, it is evident that the resolution groups had a significantly lower score on perceived conflict than the avoidance group, who obtained a significantly lower score than the excessive group.

In order to attempt to distinguish the constructs of conflict resolution and conflict, a one-way ANOVA was conducted using excessive, avoidance, and resolution groups as the IV and conflict resolution scores as the DV. The rationale for this analysis was that conflict scores for the excessive group were significantly higher than the avoidance group, which had significantly higher scores than the resolution group. In fact, the

Table 4.

ANOVA Results for Conflict Resolution Groups and Adjustment and Conflict Measures.

\begin{tabular}{cccccc}
\hline Measure & F-Statistic & $\begin{array}{c}\text { Tukey HSD } \\
\text { comparisons }\end{array}$ & Category & $M$ & $S D$ \\
\hline LSS & $15.80^{* * *}$ & $\mathrm{R}<\mathrm{A}, \mathrm{E}$ & $\mathrm{A}(\mathrm{N}=52)$ & 5.23 & 3.78 \\
& & & $\mathrm{E}(\mathrm{N}=85)$ & 5.55 & 3.70 \\
& & & $\mathrm{R}(\mathrm{N}=190)$ & 3.37 & 2.94 \\
GSI & $19.31^{* * * *}$ & $\mathrm{R}<\mathrm{A}, \mathrm{E}$ & $\mathrm{A}(\mathrm{N}=52)$ & .99 & .63 \\
& & & $\mathrm{E}(\mathrm{N}=85)$ & .95 & .65 \\
& & & $\mathrm{R}(\mathrm{N}=190)$ & .58 & .49 \\
FSLQ & \multirow{2}{*}{$18.17^{* * *}$} & $\mathrm{R}>\mathrm{A}, \mathrm{E}$ & $\mathrm{A}(\mathrm{N}=52)$ & 52.92 & 11.38 \\
& & & $\mathrm{E}(\mathrm{N}=85)$ & 55.28 & 12.07 \\
& & & $\mathrm{R}(\mathrm{N}=190)$ & 61.89 & 10.98 \\
Conflict & $63.46^{* * *}$ & $\mathrm{R}<\mathrm{A}<\mathrm{E}$ & $\mathrm{A}(\mathrm{N}=52)$ & 3.62 & 2.07 \\
& & & $\mathrm{E}(\mathrm{N}=85)$ & 5.06 & 2.18 \\
& & & $\mathrm{R}(\mathrm{N}=190)$ & 2.23 & 1.80 \\
\hline
\end{tabular}

Note. Conflict = family conflict score; $\mathrm{A}=$ avoidance group; $\mathrm{E}=$ excessive group; and $\mathrm{R}=$ resolution group; ${ }^{* * *} \mathrm{p}<.001$. mean conflict scores for the avoidance group was similar to the sample mean. This suggests that the avoidance group would not be at risk for maladjustment as a function of perceived conflict. If conflict resolution is a distinct construct from perceived conflict, it was hypothesized that FCRS scores for the avoidance and excessive groups would be significantly different (lower) from the resolution group and that FCRS scores for the avoidance and excessive groups would not differ. Results of the analysis yielded a significant $F\left(F_{2,324}=182.43, p<.001\right)$. Tukey HSD post-hoc comparisons were conducted and the results of these analyses confirm the hypothesis that the resolution group was significantly different from the avoidance and excessive groups, who were not significantly different from each another.

\section{Discussion}

This study aimed to develop a measure of family conflict resolution (FCRS) and to provide preliminary reliability and validity data. Items for this measure were either adapted from existing measures with well-established reliability and validity (e.g. CPIC and CTS2) or were rationally developed and incorporated into the measure using a peer review process.

\section{Preliminary Psychometric Properties of the FCRS}

The measure was found to have high internal consistency. Additional analyses sought to address construct validity of the measure and it was found that FCRS scores were negatively correlated with measures of conflict. These results suggest that the measures of conflict resolution and conflict tap into distinct, but related constructs. FCRS scores were found to have significant negative correlations with measures of maladjustment and significant positive correlations with a measure of life satisfaction, lending support to its convergent construct validity.

Furthermore, high, middle, and low FCRS scores were found to be related to measures of positive and negative adjustment at both statistically significant and clinically meaningful levels. This indicates that low levels of family conflict resolution were related to higher levels of maladjustment and high levels of family conflict resolution were associated lower levels of maladjustment. Results also showed that high family conflict resolution was associated with high levels of life satisfaction, or positive adjustment.

In examining the item content of the FCRS, principal component analysis yielded two factors: positive/neutral resolution and negative resolution. It can be argued that neutral items should not be grouped with positive resolution items. In fact, neutral resolution items might not be considered useful because high scores on the FCRS should be indicative of high levels of positive resolution (factor 1) and low scores should imply high levels of negative resolution (factor 2). For the instrument to serve this purpose, items that appear neutral and that load on the neutral factor need to be revised or removed.

\section{Conflict and Conflict Resolution: Are These Distinct Constructs?}

Previous unpublished research (Roskos, 2004) has shown a pattern of correlations between perceived conflict and adjustment that is similar to the pattern of correlations between fami- 
ly conflict resolution and adjustment found in this study. Additionally, the statistically and clinically meaningful relationships between high, middle, and low conflict groups and adjustment are also similar to high, middle, and low family conflict resolution group relationships with adjustment. This raises the question: are perceived conflict and family conflict resolution actually distinct constructs that are being measured? The distinction between these constructs was demonstrated in this study by the analysis of conflict and FCRS scores for the avoidance, excessive, and resolution groups. Due to the fact that excessive, avoidance, and resolution groups differentially predict conflict and conflict resolution scores, there appears to be some distinction between these constructs. These results also may indicate a measure of conflict resolution (e.g. the FCRS) may better detect individuals in the avoidance group who may be at risk for maladjustment. This suggests that it is important to assess both conflict and conflict resolution in order to accurately make clinical judgments regarding psychological adjustment when working with children, adolescents, young adults, and their families.

\section{Clinical Relevance of Conflict Resolution and Conflict Avoidance}

Beyond the goal of initiating the development of a measure of family conflict resolution, this study also examined conflict avoidance and its relationship with perceived conflict and positive and negative aspects of adjustment. The conflict avoidance group reported average levels of perceived conflict but exceeded the cutoff score for the identification of distress or maladjustment. Typically, research and clinical work has focused on expressed conflict, but based on these results, it appears that conflict avoidance is associated with maladjustment. Our results indicate that those who self-report avoidance of conflict do not perceive excessive conflict to exist, but are clearly at risk for maladjustment. To our knowledge, measures of family conflict are not necessarily screening for avoidance of conflict as a potential problem. Based on these results, avoidance of conflict may be a clinically meaningful risk factor for maladjustment that warrants additional inquiry.

Although examination of moderator effects was not the focus of this study, it is proposed that conflict resolution has the potential to serve as a buffer against maladjustment. The resolution group means were consistently below the clinical cutoff score on the LSS and were always clinically and statistically lower than both the excessive and avoidance group means on measures of maladjustment. Individuals who viewed their families as resolving conflict were less likely to be maladjusted and more likely to be satisfied with their lives than those who viewed their families as having either excessive conflict or as avoiding conflict. Conflict resolution, therefore, is related to adjustment and further research into the nature of this relationship needs to be conducted.

\section{Methodological Issues}

The greatest methodological limitation of this study is that data were collected retrospectively using only self-report measures. But, this study addressed research questions that were unique and aimed to build on existing family research by tapping into aspects of family conflict that have been recognized as in need of empirical examination (specifically, conflict resolution). Additionally, there are several methodological strengths that improve the study's robustness. The statistical power of the study was adequate due to the large sample size and the reliability and validity of the measures used were strong. It is also important to note that the sample means on all measures used in this study were near the normative means for the instruments in this age group. This allows the results to more easily be applied to young adults in a general fashion. Finally, psychological adjustment was assessed using multiple measures of the same construct (LSS and GSI).

\section{Future Directions}

Future directions would require additional study of the properties of the FCRS. Our analysis of the FCRS showed similar findings in relation to measures of adjustment using two different scoring methods, but the distribution of scores was significantly skewed when Likert items were not included in the total score. This study provides the impetus for further development and for a more rigorous evaluation of the measure being proposed. Different scoring strategies for the measure need to be explored due to the fact that the total score is based on differentially weighted items. Subsequent steps might be to further examine the properties of the true/false items and Likert items independently, or consider adapting the measure so that all items are in a Likert format. When scoring methodology is clarified, examination of the psychometric properties with further scrutiny is warranted (i.e. test-retest reliability), as well as cross-validation studies of the FCRS in younger samples. Following refinement of the measure or development of other measures, researchers might explore the effects of successful conflict resolution as a mediator or moderator variable (resiliency factor) in the relationship between conflict and maladjustment. Examination of these variables in a clinical sample might better inform practitioners of their implications and utility in a clinical setting.

\section{References}

Borrine, L. M., Handal, P. J., Brown, N. Y., \& Searight, H. R. (1991). Family conflict and adolescent adjustment in intact, divorced, and blended families. Journal of Consulting and Clinical Psychology, 59, 753-755.

Cochran, C. D., \& Hale, W. D. (1985). College student norms on the brief symptom inventory. Journal of Clinical Psychology, 41, 777-779.

Cummings, E. M., Ballard, M., El-Sheikh, M., \& Lake, M. (1991). Resolution and children's responses to interadult anger. Developmental Psychology, 27, 462-470.

Cummings, E. M., Goeke-Morey, M. C., Papp, L. M., \& Dukewich, T. L. (2002). Children's responses to mothers' and fathers' emotionality and tactics in marital conflict in the home. Journal of Family Psychology, 16, 478-492.

Cummings, E. M., Iannotti, R. J., \& Zahn-Waxler, C. (1985). The influence of conflict between adults on the emotions and aggression of young children. Developmental Psychology, 21, 495-507.

Davies, P. T., \& Cummings, E. M. (1994). Marital conflict and child adjustment: an emotional security hypothesis. Psychological Bulletin, 116, 387-411.

Derogatis, L. R., \& Spencer, P. M. (1982). Brief Symptom Inventory: Administration, scoring, and procedure manual. Baltimore: Clinical Psychometric Research. 
DuRocher-Schudlich, T. D., Papp, L. M., \& Cummings, E. M. (2004). Relations of husbands' and wives' dysphoria to marital conflict resolution strategies. Journal of Family Psychology, 18, 171-183.

El-Sheikh, M. (1997). Children's responses to adult-adult and motherchild arguments: The role of parental marital conflict and distress. Journal of Family Psychology, 11, 165-175.

Flanagan, J. C. (1978). A research approach to improving our quality of life. American Psychologist, 33, 126-147.

Grych, J. H., Seid, M., \& Fincham, F. D. (1992). Assessing marital conflict from the child's perspective: The children's perception of interparental conflict scale. Child Development, 63, 558-572.

Handal, P. J. \& Moore, C. (1987). The influence of physical, psychological, and sociocultural supplies on mental health and life satisfaction: A test of Caplan's supply model. Journal of Primary Prevention, 7, 132-142.

Handal, P. J., Gist, D., Gilner, F. H., and Searight, H. R. (1993). Preliminary validity data for the Langner and the B.S.I. as mass screening instruments for adolescent adjustment. Journal of Clinical Child Psychology, 22, 382-386.

Handal, P. J., Tschannen, T., and Searight, H. R. (1998). The relationship of child adjustment to husbands' and wives' marital distress, perceived family conflict, and mothers' occupational status. Child Psychiatry and Human Development, 29, 113-126.

Handal, P. J., LeStiebel, N., Dicarlo, M., \& Gutzwiller, J. (1999). Perceived family environment and adjustment in American-born and immigrant Asian adolescents. Psychological Reports, 85, 1244-1249.

Handal, P. J., Gist, D., Gilner, F. H., \& Searight, H. R. (1993). Preliminary validity data for the Langner and the B.S.I. as mass screening instruments for adolescent adjustment. Journal of Clinical Child Psychology, 33, 382-386.

Kleinman, S. L., Handal, P. J., Enos, D., Searight, H. R., \& Ross, M. J. (1989). Relationship between perceived family climate and adolescent adjustment. Journal of Clinical Child Psychology, 18, 351-359.

Langner, T.S. (1962). A 22-item screening score of psychiatric symptoms indicating impairment. Journal of Health and Human Behavior, 3, 269-276.

Moos, R. H., \& Moos, R. S. (1986). Family Environment Scale manual (2nd ed.). Palo Alto, CA: Consulting Psychologists Press.

Nelson, W. L., Hughes, H. M., Handal, P., \& Katz, B. (1993). The relationship of family structure and family conflict to adjustment in young adult college students. Adolescence, 28, 29-40.

Roskos. P. T. (2004). Family conflict and its effects on adjustment Unpublished Master's Thesis, Saint Louis University, St. Louis, MO.

Straus, M. A. (1979). Measuring intrafamily conflict and violence: The Conflict Tactics (CT) scales. Journal of Marriage and the Family, 41, $75-88$.

Straus, M. A. (1990). The conflict tactics scale and its critics: an evaluation and new data on validity and reliability. In M. A. Straus and R. J. Gelles (Eds.), Physical violence in American families: Risk factors and adaptations in violence in 8,145 families (pp. 49-73). New Brunswick, NJ: Transaction Publishing.

Straus, M. A., Hamby, S. L., Boney-McCoy, S., \& Sugarman, D. B. (1996). The revised conflict tactics scales (CTS2): development and preliminary psychometric data. Journal of Family Issues, 17, 283316 . 